\title{
Study on Translation Work Force Training under the Influence of Chinese Tea Culture Communications
}

\author{
Lingyun Chu \\ School of Foreign Languages \\ Harbin University of Commerce \\ Harbin, China
}

\begin{abstract}
China is the birthplace of tea. Tea culture is one of the most important components of Chinese culture that enjoys a long history of 5000 years. As Chinese reform deepens and develops, Chinese culture exchanges with other countries grow. Chinese tea culture has mingled with the local cultures and form different tea cultures in different countries and regions. In recent decades, tea culture, the most significant element in cultural exchanges, has exerted great influence in foreign exchanges such as Chinese tea culture exhibition, which is the channel for foreigners to deepen their understanding of China.
\end{abstract}

Keywords-Chinese tea culture; foreign communications; translation work force training

\section{Connotation of Chinese Tea Culture}

According to Modern Chinese Dictionary, culture is defined as the overall materialistic and spiritual treasure made during the process of social development, especially the spiritual value. In Chinese, "culture" contains the meaning of civilization and cultivation. Therefore tea culture refers to spiritual connotation specifically. To Chinese, tea has special connotation, which has deeply taken roots in the Chinese traditional civilization. From the ancient times, tea culture has been immersed in the three major religions and teachings --Confucianism, Taoism and Buddhism, which has exerted great influence on the ideas of Chinese tea culture. Confucians cultivated virtues through tea that advocated the Doctrine of Mean and Harmony and aimed at cultivation, social peace, and great order across the land. Taoists cultivated one's minds through tea in pursuit of tranquility and indifference to fame and wealth. Buddhists cultivated personality through tea in hope of peace and quiet to come to understand the essence of Buddhism. As a result, the mindsets and virtues in the quest for tea cultures have been elevated to Chinese social conventions and norms.

Sponsors: 2016 Project of Teaching Reform and Teaching Research in Harbin University of Commerce "Study of Flipped Classroom in Business English Translation Course" (HSDJY08(Z)); Education and Scientific Planning of Heilongjiang Province "Study of Teaching Mode of Business English Translation" (GJD1215018); 2016 Project of Academic Team Building in Harbin University of Harbin Commerce "Research on Translation of Publicity Materials from the Perspective of Medio translatology" (2016TD017)

\section{SIGNIFICANCE OF FOREIGN COMMUNICATIONS OF Chinese Tea Culture}

In 2008, Chinese GDP has been ranked the third place globally. In 2009, GDP increased by $8.7 \%$ on a year-on-year basis, which showed the fact that Chinese Hard Power had stepped into a new phase. However, the cultural power in soft power has always been dominated by the western civilization. Foreign cultural exchange workers have encountered unprecedented challenges together with opportunities. On one hand, as the universal economies have been integrated gradually, the people around the world have participated in competition and cooperation consciously and unconsciously; on the other hand, local wars never cease to an end globally so that the resources on the earth is on the verge of running out which explains the deterioration of human living conditions. People of all nations are expecting the peaceful and harmonious world. The ideas of Chinese tea culture agree with people's expectations. Chinese tea culture centers on spiritual pursuit of integration of human and nature and social cohesion, which will definitely play a positive role in keeping and promoting peace.

\section{QUALITIES OF TRANSLATION WORK FORCES}

With the accelerated advancement of economic strength, China is the indispensable part of the world, and the world is a crucial element in China's growth. Therefore, tea culture, the distinguished part of the Chinese culture, has attracted global attention. In current years, Chinese tea culture has amazed the world in Olympics and World Expo. With the efforts of Chinese units concerned, tea culture exhibitions have been held in many countries. In the course of foreign exchanges, translation of texts related to tea culture has put in a very important position in addition to the research of tea itself. Training of translation work force is in urgent needs after all over $80 \%$ of publications are in English.

Translation is the bridge of foreign communications of tea cultures. So the translation talents of Chinese tea culture are expected to be ones who know something of everything and everything of something, that is to say, ones who know well about tea and tea culture and have a good mastery of a foreign language. For a long time, college graduates know nothing about other majors and meanwhile graduates of other majors know little about a foreign language. The translation work 
force that is able to take the task of foreign exchanges of tea culture should have the following qualities:

\section{A. Good Language Skills Relevant to Tea Culture}

Good language skills and qualified translation skills are the basic requirements for translation work force. As for the English workers of tea cultures, language skills and translation techniques are the basic qualifications. In order to achieve the goal of cultural exchanges of tea, the translators should understand the connotation of tea culture and then convey its meaning to target readers. In the first place, translators should be equipped with expressions related to tea, such as green tea, black tea, Oolong, scented tea, tea bag, tea set, tea tools, tea appliances, tea pot, tea kettle, tea spoon, tea tray, tea table, tea cake, tea basket, tea party, tea garden, tea room and tea house.

Translators have to be scrupulous and devoted to deeply understand tea culture and the use of the English language in order to comprehend the essence of tea culture. In the Chinese proverb "Sipping tea is sipping life itself", sipping is often translated as "savoring". Savoring is not the equivalent to the Chinese character "Pin" although "savoring" means to taste or enjoy with zest; to relish according to Contemporary English Dictionary. Based on BNC (British National Corpus with over 0.1 billion English words) and COCA (Corpus of Contemporary American English with over 0.4 billion English words), there is no evidence of the collocation of savor and tea, which is the proof that the westerner never the word "savor" when they talk about tea. However, there are more than 200 items to prove the colloquial collocation of sip and tea. What's more, sipping tea is an art. In tea culture, tea is closely related to poems, dance, music, painting, religions, pottery and tea performances. Of course, it is necessary to take the aesthetic effects into consideration in translation to better convey the meanings in source texts, be accepted by target readers in a better manner and to fulfill the needs of foreign exchanges.

\section{B. Translators' Sensitivity and Dedication to Spread Chinese Tea Culture}

In curriculum of English majors, there usually are such courses as British and American Civilizations and Western Cultures to help the English learners to know well about target cultures to arouse learners' cross-cultural awareness. In fact, most of the colleges refuse to open course of Chinese culture, let alone courses of a specific culture. Therefore it is essential for universities and colleges to open courses of culture in accordance with their local specialties and courses with more realistic value in order to enhance students' comprehensive abilities as well as their qualities of humanities. By acquiring information about their hometowns, the students may love their hometown and homeland more, improve their abilities to preserve and spread the Chinese culture.

\section{TRANSLATION WORK FORCE TRAINING UNDER THE GUIDANCE OF FOREIGN EXCHANGES OF CHINESE TEA Culture}

Nowadays, there are totally 160 countries and regions with customs of drinking tea. The manufacturing volume of tea occupies over $30 \%$ of the international volume; the export volume is ranked the fifth place. But it should be admitted that the traditional culture especially the folk culture has been alienated and faded out. Tea culture together with its spiritual connotation and values has been gradually weakened. The exchanges of spiritual treasure of tea culture don't fit those of materialistic treasure, which blocks the development of spreading tea culture and tea economy. The translation work force who are acquainted with the information of tea, Chinese culture and the English language should be trained with many efforts to change the circumstances, carry forward China's civilization and to promote the well-balanced economic development.

\section{CONCLUSION}

Chinese civilization has set a heavy cultural foundation for Chinese tea culture. Through foreign exchanges of tea culture, the ties between the Chinese people and people of all over the world will be strengthened and promoted and the integration of tea culture with tea industries will be accelerated and furthered. With frequent exchanges of tea culture, tea economy will certainly play significant role in social and economic advancement. Therefore it is pressing to nurture translation work force of language skills and humanistic qualities. In order to solve the problem, we should open the courses of Chinese culture including tea culture to English majors and moreover, pave a solid foundation for future language training with scrupulous attitude. On the other hand, translators' sense of sensitivity and sense of dedication should also be fostered to shoulder the responsibility of foreign exchanges and communications.

\section{REFERENCES}

[1] Laura. Wright, and Jonathan. Hope, "Stylistics: a practical course book," London and New York: Routledge, 2006.

[2] Chen Wenhua, Teaching of tea culture in Jiangxi Province. Agricultural Archaeology, vol. 4, 2012, pp. 54-58.

[3] Ren Xinlai, Impact of Confucianism, Taoism and Buddhism on development of tea culture of Tang Dynasty, Wen Bo, vol.2, 2012 , pp.77-79.

[4] Wang Junwei, Connotation of tea culture in Poyang Lake, Agricultural Archaeology, vol.5, 2013, pp.101-104.

[5] Yu Yue, Exchange strategies of tea culture in Poyang Lake and local culture in Jiangxi Province, Agricultural Archaeology, vol.3, 2015, pp.55-59. 